\title{
Exchange Market Pressure in Central European Countries from the Eurozone Membership Perspective*
}

Daniel Stavarek*

\section{Abstract:}

This paper estimates the exchange market pressure (E M P) in four C entral E uropean countries (C zech Republic, H ungary, Poland, Slovakia) over the period 1993-2006. Therefore, it is one of very few studies focused on this region and the very first paper applying concurrently model-dependent as well as model-independent approaches to E M P estimation to these countries. The results obtained suggest that the approaches lead to inconsistent findings. They often differ in identification of the principal development trends, as well as the magnitude and direction of the pressure. The paper provides evidence that a shift in the exchange rate regime towards the quasi-fixed E RM II should not stimulate E M P growth. H owever, it is highly probable that some episodes of the excessive E M P will make the fulfillment of the exchange rate stability criterion more difficult in all of the countries analyzed.

Keywords: Exchange Market Pressure, Model-dependent Approach, Model-independent Approach, European Union, Euro-candidate Countries

$$
\text { JEL: C32, E42, F31, F36 }
$$

DOI: $10.2478 / \mathrm{v} 10033-008-0010-\mathrm{Z}$

\section{Introduction}

Ten countries from Central and Eastern Europe joined the European Union (hereafter EU) in the spring of 2004 and in 2007 completed the transformation from centrally planned economies to market economies. Moreover, it is expected that they will also join the Eurozone and implement the Euro as their legal tender. However, membership in the Eurozone is conditioned by fulfillment of the Maastricht criteria. One criterion of which is the national currency's stability in the period preceding entry into the Eurozone.

This criterion is associated with specific exchange rate regime, ERM II, which must be adapted by all countries with regimes whose principles do not correspond with the ERM II's spirit The group of incompatible regimes includes crawling pegs, free floats or managed floats without a mutually agreed central rate and pegs to anchors other than the Euro. Itmeans that all EU new Member States except for

A cknowledgement

Research behind this paper was supported by the Czech Science Foundation within the project GAČR 402/08/0067 "Financial Integration of the New EU Member States with Eurozone".
Bulgaria, Estonia and Lithuania had or will have to modify their exchange rate arrangement when joining ERM II. The Czech Republic, Hungary, Poland and Romania currently use flexible exchange rate arrangements. Slovakia and to a lesser extent Slovenia also maintained a flexible regime before entry into the ERM II. Such a change toward a less flexible exchange rate system could increase susceptibility of the countries to currency crises and pressures in foreign exchange markets.

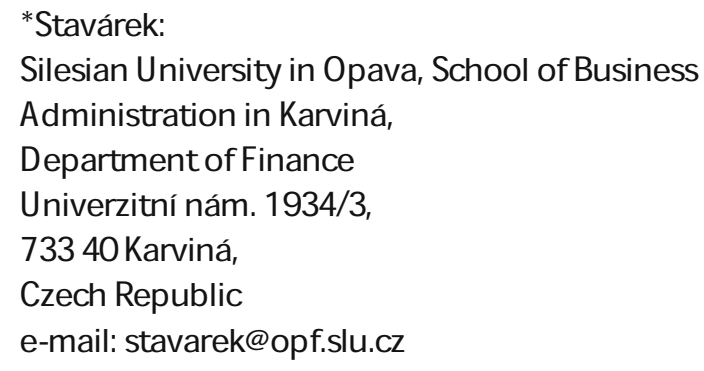


Therefore, the aim of this paper is to estimate exchange market pressure (EMP) in the Czech Republic, Hungary, Poland and Slovakia (hereafter EU4) during the period 1993-2006. Since all countries applied both a fixed and flexible exchange rate regime, the time span chosen allows us to compare magnitude of tensions in the foreign exchange market in different exchange rate environments. This kind of analysis has important policy implications as Slovakia has already switched to a less flexible regime and the remaining countries will make this unavoidable step in the near future.

The paper is structured so that Section 2 describes the meaning and theoretical concepts of EMP and provides a review of the relevant literature. In Section 3, the models and data used are cited. Section 4 reports the empirical results and the conclusions are presented in Section 5.

\section{Exchange Market Pressure and Literature Review}

\subsection{Meaning and Concepts of Exchange MarketPressure}

The term "exchange market pressure" usually refers to changes in two cardinal variables describing the external sector of any economy: official international reserve holdings and the nominal exchange rate. However, the notion of EMP was defined explicitly for the first time in Girton and Roper (1977). The EMP index in this study is the simple sum of the rate of change in international reserves and the rate of change in the exchange rate. However, since the measure is derived from a highly restrictive monetary model, the formula cannot be applied to other models.

The original concept of EMP has been modified and extended by many researchers. For example, Roper and Turnovsky (1980) and Turnovsky (1985) introduced the idea of using a small open-economy model and extended the original model by substituting the simple monetary approach by an IS-LM framework with perfect mobility of capital. Furthermore, the two EMP components were no longer equally weighted as in the Girton-Roper model.

A notable contribution to the EMP theory was provided by Weymark (1995, 1997a, 1997b, 1998). She revised the models mentioned above and introduced a more general framework in which the models are both special cases of the generalized formula. She introduced and estimated a parameter (conversion factor) standing for the relative weight of exchange rate changes and intervention in the EMP index. Since all previous EMP definitions stemmed from a specific model, Weymark also proposed a modelindependent definition of EMP as:

The exchange rate change that would have been required to remove the excess demand for the currency in the absence of exchange market intervention, given the expectations generated by the exchange rate policy actually implemented (Weymark 1995, p.278).

Many researchers have criticized the most undesirable aspect of the EMP measure, dependency on a particular model, and proposed some alternative approaches called model-independent. A simpler and model-independent EMP measure was originally constructed in Eichengreen et al. (1994, 1995). According to this approach, EMP is a linear combination of a relevant interest rate differential, the percentage change in the bilateral exchange rate and the percentage change in foreign exchange reserves. Contrary to Weymark's approach, the weights are to be calculated from sample variances of those three components with no need to estimate any model.

The measure by Sachs et al. (1996) consists of the same elements, but each weight in the EMP index is calculated with respect to standard deviations of all components included instead of using only standard deviation of the respective component.

Kaminsky etal. (1998) and Kaminsky and Reinhart (1999) substituted the interest rate differential by a relevant interest rate in the country analyzed. Furthermore, the weights on the reserves and interest rate terms are the ratio of the standard error of the percentage change of the exchange rate over the standard error of the percentage change of reserves and the interest rate differential, respectively. An approach stemming from Eichengreen et al. (1996) was also followed by Pentecost et al. (2001). However, they determined the weights using principle components analysis.

\subsection{Review of Relevant Empirical Literature}

Since its introduction, EMP has attracted the attention of many researchers and a great number of theoretical as well as empirical papers have been published. Whereas some empirical papers are focused straight on estimation of EMP in a variety of regions and countries, other studies use the EMP measure as an element of a subsequent analysis examining currency crises, monetary policy, foreign exchange intervention, exchange rate regime and other issues. We only refer to studies analyzing EMP in EU 4 in the following literature review.

The first study estimating EMP in, among others, the Czech Republic and Poland, was by Tanner (2002). Using the Girton-Roper model, he examined the relationship between EMP and monetary policy in a vector autoregression system. Regarding the EMP calculated in the Czech Republic and Poland, they were modest in comparison to other countries and very similar to each other. However, EMP in Poland was twelve times higher than in the Czech Republic during the Asian crisis in the second half of the 1990s. Although a positive relationship between EMP and domestic money supply was revealed in both countries, they were not as significant and straight as in other countries. 
A more specific application of the Tanner (2002) approach is Bielecki (2005). The paper concentrates only on Poland from 1994-2002. The results indicate that domestic credit reacted in a direction counter to innovations to EMP. Furthermore, Bielecki compared two EMP measurescalculated under alternative methodologies (using all foreign reserve changes and pure official foreign exchange intervention data) and came to the conclusion that the appreciation pressure prevailed over the sample period. However, using the pure intervention data in the EMP estimation provided more realistic and robust results.

Van Poeck et al. (2007) used EMP as an indicator of currency crisis and addressed the question whether currency crises in the Euro-candidate countries have been more frequent in fixed, intermediate or flexible exchange rate arrangements. The authors found that EMP was marginally smaller in countries and periods characterized by an intermediate exchange rate regime as compared to those with a floating arrangement. Regarding EU 4, the most critical quarters (excessive EMP) occurred in Hungary during the fixed peg regime and in Poland when a crawling peg was being applied.

Very similar conclusions were drawn in Stavárek (2005) where EMP in the Czech Republic, Hungary, Poland and Slovenia in 1993-2004 are estimated. The study applied the EMP measure proposed in Eichengreen et al. (1995) and the results obtained suggest that the Czech Republic and Slovenia went through considerably less volatile development of EMP than Hungary and Poland.

\section{Measuring the Exchange MarketPressure: Model and D ata}

\subsection{Model-D ependent Approach}

This study originally stems from Weymark (1995) and Spolander (1999) and applies the following formula for EMP calculation:

$$
E M P_{t}=\Delta e_{t}+\eta(1-\lambda) \Delta r_{t}
$$

where $\Delta e_{t}$ is the percentage change in exchange rate expressed in direct quotation (domestic price for one

unit of foreign currency), $\Delta r_{t}$ is the change in foreign exchange reserves scaled by the one-period-lagged value of money base and $\eta$ is the conversion factor which has to be estimated from a structural model of the economy and

$\lambda$ is the proportion of foreign exchange intervention that is sterilized by a change of domestic credit.

The conversion factorrepresentselasticity thatconverts observed reserve changes into equivalent exchange rate units. This EMP formula assumes that the central bank's monetary policy is completely independent of demand and supply conditions for the domestic currency in the international foreign exchange market. This means that autonomous money market interventions, i.e. changes in domestic credit not due to sterilization operations, are not assumed to be an instrument of exchange rate policy (Spolander 1999, p. 23).

For practical estimation of EMP the small open economy monetary model summarized in equations (2)-(8) was applied.

$$
\begin{aligned}
& \Delta m_{t}^{d}=\beta_{0}+\Delta p_{t}+\beta_{1} \Delta c_{t}-\beta_{2} \Delta i_{t} \\
& \Delta p_{t}=\alpha_{0}+\alpha_{1} \Delta p_{t}^{*}+\alpha_{2} \Delta e_{t} \\
& \Delta i=\Delta i_{t}^{*}+E_{t}\left(\Delta e_{t+1}\right)-\Delta e_{t} \\
& \Delta m_{t}^{s}=\Delta d_{t}^{a}+(1-\lambda) \Delta r_{t} \\
& \Delta r_{t}=-\bar{p}_{t} \Delta e_{t} \\
& \Delta d_{t}^{a}=\gamma_{0}+\Delta y_{t}^{\text {trend }}+\left(1-\gamma_{1}\right) \Delta p_{t}-\gamma_{2} y_{t}^{\text {gap }} \\
& \Delta m_{t}^{d}=\Delta m_{t}^{s}
\end{aligned}
$$

where $p_{t}$ is domestic price level, $p_{t}^{*}$ is foreign price level, $e_{t}$ denotes exchange rate (in direct quotation), $m_{t}$ is nominal money stock (the superscript $d$ represents the demand and $S$ the supply), $c_{t}$ is real domestic income, $i_{t}$ is nominal domestic interest rate, $i_{t}^{*}$ denotes nominal foreign interest rate, $E_{t}\left(\Delta e_{t+1}\right)$ is expected exchange rate change and $\lambda$ is proportion of sterilized intervention. All variables up to this point are expressed in natural logarithm. Next, $d_{t}^{a}$ is autonomous domestic lending by the central bank and $r_{t}$ is the stock of foreign exchange reserves, both divided by the one period lagged value of the money base. $y_{t}^{\text {trend }}$ is the long-run trend component of real domestic output $y_{t}$ and $y_{t}^{g a p}$ is the difference between $y_{t}$ and $y_{t}^{\text {trend }}$. The sign $\Delta$ naturally denotes change in the respective variable.

Equation (2) describes changes in money demand as a positive function of domestic inflation and changes in real domestic income and a negative function of changes in the domestic interest rate. Equation (3) defines the purchasing power parity condition attributing the primary role in domestic inflation determination to exchange rate changes and foreign inflation. Equation (4) describes uncovered interest rate parity. Equation (5) suggests that changes in the money supply are positively influenced by autonomous changes in domestic lending and nonsterilized changes in the stock of foreign reserves. Equation (6) states that changes in foreign exchange reserves are a function of the exchange rate and a time-varying response coefficient. Equation (7) describes the evolution 
of the central bank's domestic lending. Whereas domestic inflation and changes in trend real output changes are positive determinants of the domestic lending the gap between real output and its trend has a negative impact on domestic lending activity. Equation (8) defines a money market clearing condition that assumes money demand to be continuously equal to money supply.

By substituting equations (3) and (4) into equation (2) and substituting equation (7) into equation (5) and then using the money market clearing condition in equation (8) to set the resulting two equations equal to one another, it is possible to obtain the following relation:

$$
\Delta e_{t}=\frac{X_{t}+\beta_{2} E\left(\Delta e_{t+1}\right)+(1-\lambda) \Delta r_{t}}{\gamma_{1} \alpha_{2}+\beta_{2}}
$$

where

$$
X_{t}=\gamma_{0}-\gamma_{1} \alpha_{0}-\beta_{0}+\Delta y_{t}^{\text {trend }}-\gamma_{1} \alpha_{1} \Delta p_{t}^{*}-\gamma_{2} y_{t}^{g a p}-\beta_{1} \Delta c_{t}+\beta_{2} \Delta i_{t}^{*}
$$

and the elasticity needed to calculate EMP in equation (1) can be found as:

$$
\eta=-\frac{\partial \Delta e_{t}}{\partial \Delta r_{t}}=-\frac{(1-\lambda)}{\gamma_{1} \alpha_{2}+\beta_{2}}
$$

\subsection{Model-Independent Approach}

As mentioned above, Eichengreen et al. (1994, 1995) argued that dependency on a particular model was an undesirable feature for theEMPindex. As an alternative, they proposed the following measure of a speculative pressure:

$$
E M P_{t}=\frac{\Delta e_{t}}{e_{t}}-\frac{1}{\sigma_{r}}\left(\frac{\Delta m_{t}}{m_{t}}-\frac{\Delta m_{t}^{*}}{m_{t}^{*}}\right)+\frac{1}{\sigma_{i}}\left(\Delta\left(i_{t}-i_{t}^{*}\right)\right.
$$

where $\sigma_{r}$ is the standard deviation of the difference between the relative changes in the ratio of foreign reserves and money (money base) in the analyzed country

and the reference country $\left(\frac{\Delta m_{t}}{m_{t}}-\frac{\Delta m_{t}^{*}}{m_{t}^{*}}\right)$ and $\sigma_{i}$ is the standard deviation of the nominal interest rate differential $\left(\Delta\left(i_{t}-i_{t}^{*}\right)\right.$. Other variables are as defined in the previous specification.

However, for the practical calculation we tookinspiration from Sachs et al. (1996) and made some modifications of the EMP formula. In order to avoid the EMP measure being driven by the most volatile component we changed the weighting scheme. We also abandoned the relation between foreign reserves and money at the home and reference country. Consequently, the EMP formula based on a model-independent approach can be written as

$$
\begin{aligned}
& E M P_{t}=\left(\frac{1 / \sigma_{e}}{\left(1 / \sigma_{e}\right)+\left(1 / \sigma_{m}\right)+\left(1 / \sigma_{i}\right)}\right) \frac{\Delta e_{t}}{e_{t-1}}-\left(\frac{1 / \sigma_{m}}{\left(1 / \sigma_{e}\right)+\left(1 / \sigma_{m}\right)+\left(1 / \sigma_{i}\right)}\right) \frac{\Delta m_{t}}{m_{t-1}}+ \\
& +\left(\frac{1 / \sigma_{i}}{\left(1 / \sigma_{e}\right)+\left(1 / \sigma_{m}\right)+\left(1 / \sigma_{i}\right)}\right)\left(\Delta\left(i_{t}-i_{t}^{*}\right)\right.
\end{aligned}
$$

where $\sigma_{e}$ is the standard deviation of the rate of change in the exchange rate $\frac{\Delta e_{t}}{e_{t-1}}$ and other variables are denoted consistently with (12). $e_{t-1}$

The samples of data used in this paper cover the period 1993:1 to 2006:4, yielding 56 quarterly observations for all EU 4 countries. The data were predominantly extracted from the IMF's International Financial Statistics and the Eurostat's Economy and Finance database. The missing observations in the time series were replenished from databases accessible on the EU 4 central banks' websites. The detailed description of all data series and their sources is presented in Appendix 1.

\section{Estimation of Exchange Market Pressure}

\subsection{Model-D ependent Approach}

As is evident from the model presented in Section 3.1, the EMP estimation (1) must be preceded by the calculation of the conversion factor $\eta$ (11). However, this step is required to obtain values of the sterilization coefficient $\lambda$ (5), the elasticity of the money base with respect to the domestic price level $\gamma_{1}(7)$, the elasticity of the domestic price level with respect to the exchange rate $\alpha_{2}$ (3), and the elasticity of the money demand with respect to the domestic interest rate $\beta_{2}$ (2).

Mbre precisely, the param eter estimates are obtained by estimating the following three equations.

$$
\begin{aligned}
& \Delta m_{t}-\Delta p_{t}=\beta_{0}+\beta_{1} \Delta c_{t}-\beta_{2} \Delta i_{t}+\varepsilon_{1, t} \\
& \Delta p_{t}=\alpha_{0}+\alpha_{1} \Delta p_{t}^{*}+\alpha_{2} \Delta e_{t}+\varepsilon_{2, t} \\
& \frac{\Delta B_{t}}{B_{t-1}}-\Delta r_{t}-\Delta y_{t}^{\text {trend }}-\Delta p_{t}=\gamma_{0}+\lambda \Delta r_{t}+\gamma_{1} \Delta p_{t}+\gamma_{2} y_{t}^{\text {gap }}+\varepsilon_{3, t}
\end{aligned}
$$

Equations (14) and (15) are obtained directly from equations (2) and (3). Equation (16) is derived by substitution of (6) into (4) and noting that change in money 
supply equals the change in money base $\frac{\Delta B_{t}}{B_{t}}$ assuming the money multiplier to be constant. $\quad \overline{B_{t-1}}$ One can distinguish two types of variables included in the model: endogenous and exogenous. The endogenous variables are $\Delta m_{t}, \Delta p_{t}, \Delta e_{t}, \Delta i_{t}, \frac{\Delta B_{t}}{B_{t-1}}$ and $\Delta r_{t}$. The exogenous variables are $\Delta c_{t}, \Delta p_{t}^{*}, \Delta i_{t}^{*}, \Delta y_{t}^{\text {trend }}$ and

$\Delta y_{t}^{g a p}$. Despite the fact that $\Delta e_{t}$ does not appear on the left-hand side of any of the equations, it is the endogenous variable because the exchange rate is clearly the variable determined by this model.

The model is estimated using the two-stage least square regression technique (2SLS). The main reason is that the endogenous variables are on both sides of equations (2)(8). It means that in each equation having endogenous variables on the right-hand side, these variables are likely to correlate with the disturbance term. Thus, using the ordinary least square method would lead to biased estimates.

The 2SLSused requires the incorporation of instruments (variables uncorrelated with the disturbance term) into the estimation. To find appropriate instruments we run the first stage regressions on endogenous variables having all possible instrum ents as regressors. As possible instruments we set the contemporaneous and one-quarter lagged values of exogenous variables and one-quarter lagged values of all endogenous variables. Finally, the regressors with sufficient statistical significance were selected as instruments.

We applied Augmented Dickey-Fuller tests to examine the stationarity of the time series used. According to the character of each time series we tested the stationarity with a linear trend and/orinterceptornone of them. Tests'results allow us to conclude that the first differences of all time series are stationary. Thus, they can be used in estimation of all equations of the model. The percentage change in money base is a naturally flow variable and so already differenced and stationary. Likewise, $\mathrm{y}_{\mathrm{t}}{ }^{\text {gap }}$ is stationary on level in all countries because of its construction.

The 2SLSestimation results are presented in Appendix 2 individually for each equation. The tables also contain the list of instruments and results of some diagnostic tests. We applied a Jarque-Berra (J-B) indicator to assess normality of the residuals distribution, a Breusch-Godfrey Langrange Multiplier (LM) to test serial correlation and a White test to check heteroscedasticity. All LM tests were run with four lags. The tests indicated evidence of serial correlation in residuals from the equations and the potential heteroscedasticity was also identified in some cases. Therefore, we corrected the standard errors of parameter estimates by the Newey-West procedure. Even more frequently, the residuals seem to be nonnormally distributed. Therefore, although the t-statistics can be misleading, this does not reduce the validity of the parameter estimates. Since different equation specifications have different instruments, $\mathrm{R}^{2}$ for $2 \mathrm{SLS}$ can be negative even if a constant is used in the equation.

According to the model specification the parameters $\beta_{1}$ , $\alpha_{1}$, and $\alpha_{2}$ should be positive and $\beta_{2}, \gamma_{1}, \gamma_{2}$, and $\lambda$ should be negative. Since $\lambda$ is a fraction, its absolute value should be between zero and one.

The estimations of equation (14) provide mediocre results. The parameters $\beta_{2}$ are correctly signed in all EU4. However, the parameter is not statistically significant in Slovakia. One can see some evidence of non-normal distribution (Czech Republic, Slovakia), serial correlation (Hungary) and heteroscedasticity (Czech Republic, Hungary and Poland).

In the estimations of equation (15) we obtained very good results. The signs of all parameters are consistent

with the theoretical assumptions and important $\alpha_{2}$ parameters are significantly different from zero in all countries. On the other hand, only error term s in the Polish and Slovak equations seem to pass the standard diagnostic tests com pletely. Furtherm ore, one can find a substantially lower elasticity of the domestic price level with respect to

the exchange rate $\left(\alpha_{2}\right)$ in Poland and, to a lesser degree, in Slovakia than in other EU4.

The results from the money supply equation (16) are somewhat poorer. This is true because especially the estimation of the Polish equation led to confusing

results. The parameter $\gamma_{1}$ has an opposite sign than the theory suggests and the absolute value of the sterilization coefficient $\lambda$ exceeded the upper margin of the potential interval from zero to one. Mbreover, $\gamma_{1}$ in all EU4 except for Hungary are statistically insignificant. Neither the performance of the elasticities of the money base with

respect to the domestic output gap $\left(\gamma_{2}\right)$ are significant (again, Hungary is the exception). According to Spolander (1999, p.72) this problem stem s from different specification of the equation and, unfortunately, it is a common drawback of many studies of monetary policy rules and reaction functions.

The param eter estimates of the sterilization coefficients

$\lambda$ in all EU4 except for Hungary do not significantly differ from minus unity, which implies full sterilization. This statement is based on results of the Wald test of the null hypothesis $\lambda=-1$ However, the EU4central b anks have never publicly declared that all foreign exchange intervention has no impact on the money base. Hence, we assume that the param eter estimates of $\lambda$ indicate less than full sterilization. This assumption is in accordance with the practice of central banks from developed countries, which usually sterilize their intervention partially rather than fully. 
Table 1 sum marizes estimates of the conversion factors $\eta$ calculated for all countries using equation (11). Due to non-standard results of the estimation of equation (16) in Poland, the Polish conversion factor differs substantially from other factors in magnitude as well as sign. The extraordinary value of Polish $\eta$ is subsequently transmitted to EMP, whose extent will not correspond with the EMPscale in other EU4.

\begin{tabular}{|c|c|c|c|}
\hline Czech Republic & Hungary & Poland & Slovakia \\
\hline $\mathbf{3 . 2 2 7 4 1 9}$ & $\mathbf{0 . 9 6 3 5 0 7}$ & $\mathbf{- 6 . 2 0 7 1 8 8}$ & $\mathbf{1 . 1 6 7 8 7 4}$ \\
\hline
\end{tabular}

Source: Author's calculations

T able 1: E stimates of conversion factors

The EMPdevelopmentaccording to a model-dependent approach is graphically presented for all countries analyzed in Appendix 3. To evaluate EMP correctly it is necessary to remember some elementary facts. First, a negative value of EMPindicates that the currency is under general pressure to appreciate. On the contrary, positive EMP shows that the currency is pressured to depreciate. Second, the value of EMPrepresents the magnitude of the foreign exchange market disequilibrium, which should be removed by a respective change of the exchange rate.

The figures contain, besides the EMP curve, the lines representing 1.5 multiple of the standard deviation above and below the mean EMP value. A breach of the corridor is considered an excessive EMP, and alerts of a potential crisis. Furthermore, the graphs are divided into several sections, thus allowing one to distinguish between different exchange rate arrangements applied in EU4during the period examined.

One can find EMPdevelopment in EU4similar in many aspects. The first three years were characterized by many episodes of excessive EMP and its high volatility. The EMP estimates suggest that there was a general pressure on EU4currencies to depreciate. The principal exception was Poland, whose EMPm easurements surpassed $60 \%$ on the appreciation side in five quarters during 1993-1995. It is very hard to believe that the magnitude of money market disequilibrium would be so enorm ous that the Polish zloty (PLN) should have appreciated by $60 \%$ in order to rem ove that disequilibrium, noting the transformation process was still at a beginning stage. Moreover, Van Poeck et al. (2007) and Bielecki (2005) ob tained considerably different (and more realistic) estimations of EMP in Poland in that period.

It is worthwhile to remember that all EU4 countries applied some version of fixed exchange rate regime in 1993-1995. Furthermore, the Czech Republic and Slovakia started their existence in January 1993after the split of the former Czechoslovakia. The related currency separation, launch of new currencies, establishment of new central banks, and formation of new monetary policies had an obvious impact on data used in the estimation and consequently on the EMP figures.

Since 1996, EMPdeveloped more smoothly and free of any abnormal fluctuations. There was only one example of breaching the corridor's margin after 1995. In Hungary, EMP in 2002:1 was $-1.96 \%$, suggesting a pressure on the forint (HUF) to app reciate. A high (not excessive) EMPalso occurred at the end of 2002 . HUF was under speculative attack on the upper edge of the band, which culminated in devaluation of the central parity. In the Czech Republic, the highest EMP was identified in 2002:2 when the pressure reached $12.24 \%$, forcing the koruna (CZK) to depreciate. This reflected the necessity for a correction after the previous long-lasting appreciation and peaking at the historic high. Whereas the depreciation pressure prevailed on HUF and the Slovak koruna (SKK), the proportion of appreciation-pressure and depreciationpressure quarters was more balanced in the case of CZK in 1996-2006.

\subsection{Model-Independent Approach}

The EMPvalues obtained from the model-independent approach are substantially different from those of model-dependent ones (see Appendix 4 for graphical illustration). They differ in magnitude as well as basic development tendencies.

None of the countries analyzed experienced extraordinarily volatile development of EMP in the first three or four years of the period exam ined. Far from it, the development in the Czech Republic and Poland over that period of time was the most stable ever. Furthermore, one can find many episodes of excessive EMP in all countries during the second half of the period analyzed. Generally, the "crisis quarters" (EMP surpassing upper or lower limit) seem to occur more frequently in the modelindependent than model-dependent approach. This should be obvious, as the "no-crisis" band in the modelindependent approach is considerably tighter than the model-dependent band in three countries. However, all breaches of the limits had a temporary character. Hence, the foreign exchange market disequilibrium did not last more than one observation (quarter). It is worthwhile to mention a similarity in the very recent EMP development that was shared by three countries (Hungary, Poland and Slovakia). The pressure exceeded or approached the lower limit at the end of 2006 announcing the appreciation pressure on the national currencies.

Whereas the appreciation pressure prevailed over the entire period in the Czech Republic and Poland, the more balanced proportion of positive and negative EMP observations was revealed in Slovakia. By contrast, Hungary had to face predominantly a depreciation pressure on HUF. 
The most extreme EMPin the Czech Republic (+13.39\%) can be observed in 2004:2 Such a high depreciation pressure was caused by the increase of the Czech interest rate ab ove the Eurozone level and the subsequent change in the interest rate differential $(+210 \%)$. In Poland, we identified the most extreme EMP in 2005:4 (-20.56\%). A separate analysis of the EMP components allows us to determine the principal cause: a substantial change in the reserves-money ratio $(+122029 \%)$ driven by a massive increase in the reserve holdings.

Slovakia is the country with the most escapes from the no-crisis band, mainly on the appreciation side. However, the breaches of the corrid or were rather marginal and the most significant one was recorded in $2005: 1(-7.75 \%)$ as a consequence of growing international reserves. Slovakia also witnessed a high depreciation pressure (+9.91\%) in 1998:4, just after the shift in the exchange rate arrangement towards a managed floating. In Hungary, ignoring the very early period, we can distinguish two cases of the excessive depreciation EMP. The first $(+11.19 \%)$ occurred in $2003: 3$ following culmination of the speculative attack on appreciating HUF. In 2005:1, EMP reached an even higher level (+13.78\%) foreseeing the com ing period of a massive HUF depreciation.

\subsection{Comparison of A Iternative A pproaches}

The alternative empirical approaches to the EMP estimation resulted in considerably different findings. This can be documented by descriptive statistics of the EMP time series as well as correlation analysis. The elementary descriptive statistics are presented in Table 2 and correlation coefficients of the EMP measures in Table 3.

The only country with results signaling some degree of consistency is Hungary. The means and medians of both EMP indices have positive signs and the correlation coefficient is the highest among all countries. One can find further uniqueness in the results from Hungary. The development of the model-dependent EMP was significantly less volatile than development of the alternative model-independent EMP. This is evident in all of the following indicators: standard deviation, width of the no-crisis band, and spread between maximum and minimum values.

Totally opposite conclusions can be drawn from the remaining countries. Their most notable common attribute is the higher volatility of the model-dependent EMP. Moreover, they also share a disharmonic development of the EMP measures mirrored in the reversely signed means and medians and low and/or negative correlation coefficients. It should be reminded here that the high standard deviations and wide bands stem from the varying development in the very early stage of the estimation period.

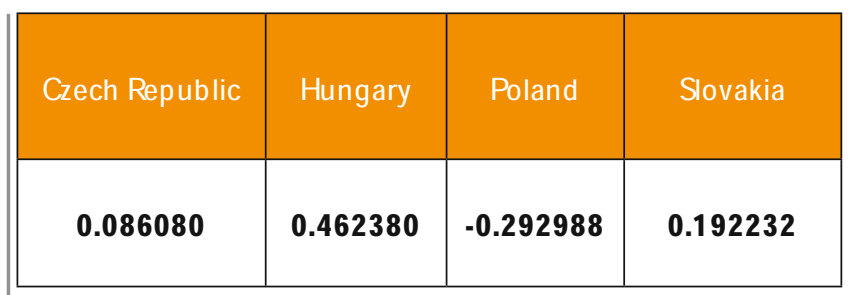

Source: Author's calculations

T able 3: Correlation coefficients of alternative exchange market pressure measures

The consistency of the two EMP indices can be also assessed by discrepancies in the identification of the crisis quarters. For that purpose, the developments of both EMP measures in each country are put together and presented in Figure 1. Moreover, Table 4 shows how many quarters were identified by the model-ind ependent approach as a crisis occurrence, and how many of these are similarly classified by the model-dependent approach if the model-independent no-crisis band applies. Table 4 also reports the number of EMP crisis observations that obtained the same sign and similar magnitude in both approaches. The results presented confirm the negligible consistency and provide evidence that the empirical tools used tend to interpret EMP development differently.

\begin{tabular}{|l|c|c|c|c|c|c|c|c|}
\hline & \multicolumn{2}{|c|}{ Gzech Republic } & \multicolumn{2}{c|}{ Hungary } & \multicolumn{2}{c|}{ Poland } & \multicolumn{2}{c|}{ Slovakia } \\
\hline & m_dep & m_ind & m_dep & m_ind & m_dep & m_ind & m_dep & m_ind \\
\hline mean & 0.0361 & -0.0015 & 0.0091 & 0.0285 & -0.1075 & -0.0080 & 0.0352 & 0.0025 \\
\hline median & 0.0036 & -0.0011 & 0.0068 & 0.0228 & -0.0362 & 0.0009 & 0.0062 & 0.0030 \\
\hline max & 0.5544 & 0.1339 & 0.0578 & 0.1504 & 0.2150 & 0.1110 & 0.7466 & 0.0991 \\
\hline min & -0.0577 & -0.1003 & -0.0199 & -0.0531 & -0.6992 & -0.2056 & -0.0891 & -0.0786 \\
\hline st. dev. & 0.0948 & 0.0371 & 0.0165 & 0.0478 & 0.2005 & 0.0554 & 0.1170 & 0.0337 \\
\hline upper & 0.1783 & 0.0488 & 0.0339 & 0.1002 & 0.1933 & 0.0751 & 0.2107 & 0.0532 \\
\hline lower & -0.1061 & -0.0612 & -0.0157 & -0.0432 & -0.4083 & -0.0912 & -0.1403 & -0.0481 \\
\hline
\end{tabular}

Source: Author's calculations

Notes: $m \_d e p$ and $m \_$ind denote model-dependent and model-independent approach respectively

T able 2: D escriptive statistics of exchange market pressure 


\begin{tabular}{||l|c|c|c|c|}
\hline & $\begin{array}{c}\text { Czech } \\
\text { Republic }\end{array}$ & Hungary & Poland & Slovakia \\
\hline m_ind crises & $\mathbf{4}$ & $\mathbf{6}$ & $\mathbf{3}$ & $\mathbf{7}$ \\
\hline m_dep crises & $\mathbf{1}$ & $\mathbf{0}$ & $\mathbf{1}$ & $\mathbf{0}$ \\
\hline same sign & $\mathbf{2}$ & $\mathbf{6}$ & $\mathbf{2}$ & $\mathbf{3}$ \\
\hline $\begin{array}{l}\text { similar } \\
\text { magnitude }\end{array}$ & $\mathbf{2}$ & $\mathbf{0}$ & $\mathbf{1}$ & $\mathbf{0}$ \\
\hline
\end{tabular}

Source: Author's calculations

Notes: $m \_d e p$ and $m$ ind denote model-dependent and model-independent approach, respectively. Similar magnitude means that the value of the $m$ _dep EMP is within interval 50\%-

$150 \%$ of the $m$ ind EMPvalue.

Table 4: Consistency of alternative approaches in identification of crises
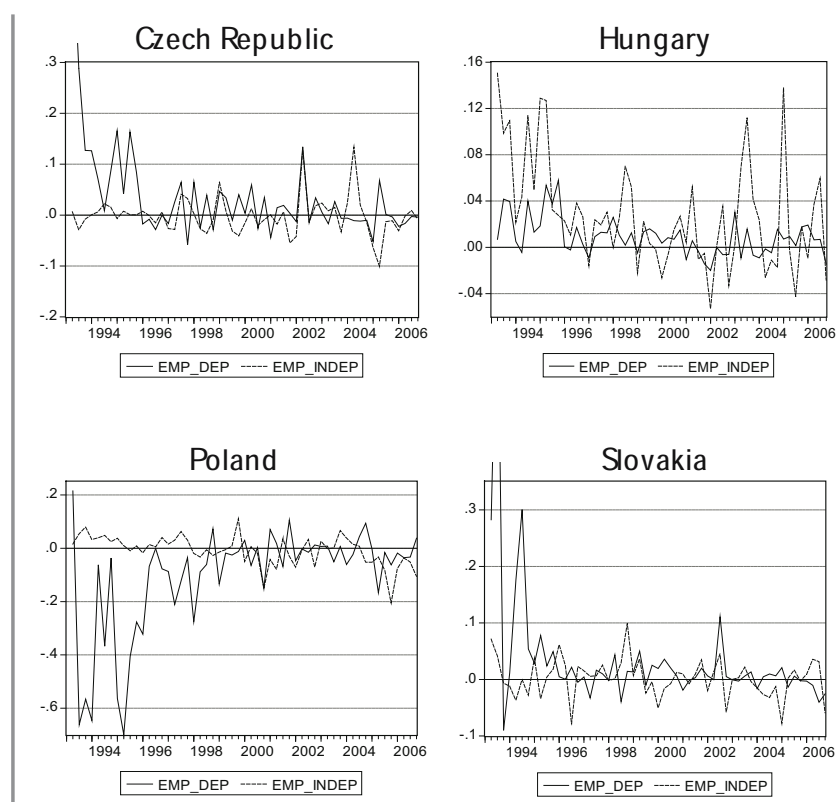

Source: Author's calculations

F igure 1: Development of exchange market pressure based on model-dependent and model-independent approaches

One of the aims of the paper is to compare EMPin various exchange rate arrangements in EU4. The comparison of the EMP standard deviations calculated over the periods with the particular exchange rate regime along with the numbers of the crisis quarters are provided in Table 5.

The results clearly suggest that any conclusion about the relationship between EMP and exchange rate regime is extrem ely sensitive to the selection of the EMPestimation method. The model-dependent and model-independent approaches lead to absolutely controversial findings on how EMPdevelop and fluctuate in the particular exchange rate arrangement. The model-dependent approach provides evidence that EMP was very stable in all EU4 during the floating-regime period and the excessive deviations of EMP occurred sporadically at that time. By contrast, the periods of fixed arrangement witnessed many episodes surpassing the level of 1.5 multiple of the standard deviation as well as substantially more volatile development. The results of the model-independent approach are totally opposite. Generally, any kind of the fixed regime paved the way for lower and less volatile EMP and also fewer crisis periods.

In order to determine whether the differences among EMPvalues in various exchange rate regimes are statistically significant we carried out a single-factor Analysis of Variance (ANOVA). The EMP observations from all EU4 were gathered in the single dataset and grouped into four categories according to the classification system used in Table 5. The ANOVA test results for both approaches are reported in Table 6.

\begin{tabular}{|c|c|c|c|c|c|c|c|c|}
\hline & \multicolumn{2}{|c|}{$\begin{array}{c}\text { Czech } \\
\text { Republic }\end{array}$} & \multicolumn{2}{|c|}{ Hungary } & \multicolumn{2}{|c|}{ Poland } & \multicolumn{2}{|c|}{ Slovakia } \\
\hline & $\begin{array}{l}\frac{O}{0} \\
\frac{0}{1} \\
E\end{array}$ & $\begin{array}{l}\stackrel{D}{.} \\
E \\
E\end{array}$ & $\begin{array}{l}\frac{O}{\theta_{0}} \\
E \\
E\end{array}$ & $\begin{array}{l}\stackrel{D}{.} \\
E \\
E\end{array}$ & $\begin{array}{l}\frac{0}{\theta_{0}} \\
E\end{array}$ & $\begin{array}{l}\stackrel{D}{.} \\
E \\
E\end{array}$ & $\begin{array}{l}\frac{0}{8} \\
\frac{0}{1} \\
\varepsilon\end{array}$ & $\begin{array}{l}\stackrel{D}{.}_{1} \\
E\end{array}$ \\
\hline $\begin{array}{l}\text { fixed } \\
\text { (crawl) } \\
\text { peg }\end{array}$ & 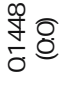 & 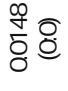 & $\begin{array}{l}\bar{\infty} \\
\bar{\delta} \\
\end{array}$ & 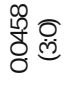 & 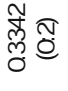 & ָั & $\begin{array}{l}\frac{\hat{Q}}{\frac{0}{0}} \\
\frac{\mathrm{O}}{\mathrm{N}}\end{array}$ & סृ \\
\hline $\begin{array}{l}\text { craw- } \\
\text { ling } \\
\text { band }\end{array}$ & 1 & 1 & 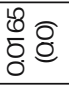 & 흐응 & $\begin{array}{l}\overline{\mathbb{D}} \\
\bar{\sigma} \\
\end{array}$ & 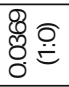 & 1 & 1 \\
\hline $\begin{array}{l}\text { floa- } \\
\text { ting }\end{array}$ & 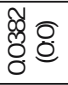 & 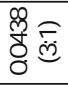 & $\begin{array}{l}\bar{N} \\
\bar{\delta} \bar{\sigma} \\
\overline{0}\end{array}$ & 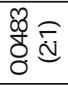 & $\overline{8} \overline{8}$ & 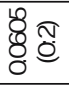 & 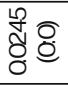 & ס्ల్ \\
\hline ERMII & 1 & 1 & 1 & 1 & 1 & 1 & $\begin{array}{l}\overline{0} 0 \\
\delta 8 \\
0\end{array}$ & $\begin{array}{l}\text { वे } \\
\text { రิ }\end{array}$ \\
\hline
\end{tabular}

Source: Author's calculations

Note: The ratio in parentheses is (number of excessive depreciation EMP: number of excessive appreciation EMP)

Table 5: Standard deviations of exchange market pressure and number of crisis quarters

\begin{tabular}{||l|c|c|c|c|c|l|}
\hline & \multicolumn{2}{|c|}{ model-dependent approach } & \multicolumn{3}{c|}{ model-independent approach } \\
\hline & $\begin{array}{c}\text { no. } \\
\text { obs. }\end{array}$ & mean & $\begin{array}{c}\text { vari- } \\
\text { ance }\end{array}$ & $\begin{array}{c}\text { no. } \\
\text { obs. }\end{array}$ & mean & vari-ance \\
\hline $\begin{array}{l}\text { fixed } \\
\text { (crawl) } \\
\text { peg }\end{array}$ & 56 & 0.00236 & 0.06289 & 56 & 0.02115 & 0.00179 \\
\hline $\begin{array}{l}\text { crawling } \\
\text { band }\end{array}$ & 44 & -0.04109 & 0.01097 & 44 & 0.01596 & 0.00118 \\
\hline floating & 115 & 0.00232 & 0.00161 & 115 & -0.00610 & 0.00244 \\
\hline ERMII & 5 & -0.01622 & 0.00026 & 5 & 0.00292 & 0.00144 \\
\hline & \multicolumn{3}{|c|}{ F-statistics: 1.162374} & \multicolumn{3}{c|}{ F-statistics: 5.646847} \\
& P-value: 0.325034 & \multicolumn{6}{c|}{ P-value: 0.000963} \\
\hline
\end{tabular}

Source: Author's calculations

Note: Critical value of F-statistics is 2646402

Table 6: A N O V A test results 
The ANOVA tests show that the exchange rate regime does not influence the average of the model-dependent EMPconsiderably, as the F-statistic is small and insignificant. On the other hand, the means of the grouped modelindependent EMPare significantly different at the $1 \%$ level. Thus, one can consider the floating arrangement to be the environment contributing to the volatile development and excessive values of EMP.

The results obtained allow us to derive some policy implications. There is no empirical justification for the a priori concerns that a shift in the exchange rate regime from floating to the quasi-fixed ERM II will stimulate EMP to increase. More likely, the basic characteristics of EMP development will be retained after the change. Hence, supposing that the recent level of EMP volatility and density of the crisis observations revealed by the modelindependent approach remain unchanged, it will cast serious doubt on the European Comm ission's requirem ent that EU4 must participate in ERM II without substantial tensions on the exchange rates.

The doub t gains im portance if the authorized fluctuation margin is likely to be asymmetric with the limits of $15 \%$ on the appreciation side and $225 \%$ on the depreciation side. Although EMP fluctuated predominantly within this narrow band in EU4 in the last four years, the depreciation part of the asymmetric band is very tight and the EMP development should be monitored closely.

Owing to some factors the EMPestimates presented and discussed previously must be viewed with some degree of skepticism. Besides the drawbacks already discussed, the model-dependent EMP in all countries developed almost in parallel with the changes in reserves over the entire period. This implies a frequent application of the central bank official intervention even in the environment of the floating exchange rate regime. However, the reality in many EU4 was different. These limitations should be addressed and eliminated in future research. We recommend use of the pure foreign exchange intervention data as the alternative to the change in reserves. The model can also be extended by the possibility of indirect intervention operating through changes in the domestic lending or interest rate.

\section{Conclusion}

In this paper, we estimated EMP for the EU4 currencies against the Euro exchange rate over the period from 1993-2006. Fundamental differences in the spirit and construction of the approaches applied are reflected in considerably different results. Thus, the two alternatives are not compatible if the data from EU4are used.

According to the model-dependent approach, EMP in the Czech Republic, Hungary and Slovakia are of similar magnitude. Whereas a depreciation pressure prevailed on HUF and SKK, no dominance of any direction of the pressure can be found in the case of CZK. The estimates of the Polish EMPare burdened by a substantial statistical insignificance. The results obtained suggest that EMP in EU4 decreased over time and was remarkably lower and less volatile during the periods of floating exchange rates than in the environment of the fixed exchange rate regime. However, there are some concerns about the validity of the param eter estim ates and consequently the EMP m easures in all EU4.

The model-independent approach puts greater emphasis on the interest rate differential, which has often been identified as one of the factors of the exchange rate determination in EU4. EMPdevelopment can be described as homogeneous during the entire period analyzed, with no episode of an abnormal volatility or exceptionally frequent occurrence of excessive EMP. While CZK and PLN were largely under ap preciation pressure, HUF was forced to depreciate and no dominance was revealed in Slovakia. However, the model-independent approach identified more crises than the model-dependent approach, including the very recent excessive appreciation pressure on three EU4national currencies.

The study does not confirm the concerns that the unavoidable shift in the exchange rate regime towards the quasi-fixed ERM II will provoke EMP to grow to excessive levels. Instead, the empirical tests suggest that the regime change will have, with a high probability, a negligible impact on EMP development. Stemming from the estimations obtained, the EU4 central banks will probably be confronted with some occasions of excessive EMPjeopardizing fulfillm ent of the exchange rate stability criterion. 마

\section{Appendix 1: D ata description}

All data are on quarterly basis and cover the period 1993:1 - 2005:4

\begin{tabular}{|l|l|}
\hline$B_{\mathrm{t}}$ & $\begin{array}{l}\text { EU4national money base } \\
\text { Obtained from IMF's International Financial Statistics (IFS) line 14 } \\
\text { (Reserve money) and then logged. }\end{array}$ \\
\hline $\mathrm{C}_{\mathrm{t}}$ & $\begin{array}{l}\text { EU4Gross national income } \\
\text { Derived by adding the net income from abroad to Gross domestic } \\
\text { product (IFS line 99B). In national accounts statistics, the total of rents, } \\
\text { interest, profits and dividends plus net current transfers is shown as "net } \\
\text { income from abroad". It was obtained from IFS by differencing current } \\
\text { account balance (IFSline 78ALD) and balance on goods and services (IFS } \\
\text { line 78AFD). Logged values. }\end{array}$ \\
\hline $\mathrm{e}_{\mathrm{t}}$ & $\begin{array}{l}\text { Nominal bilateral exchange rate of EU4currencies vis-à-vis Euro in direct } \\
\text { quotation (number of EU4currency units for one Euro) } \\
\text { Obtained from Eurostat's Economy and finance database (EEF) section } \\
\text { Exchange rates and Interest rates, line Euro/ECU exchange rates - } \\
\text { Quarterly data. Logged values. }\end{array}$ \\
\hline $\mathrm{i}_{\mathrm{t}}^{*}$ & $\begin{array}{l}\text { Eurozone 3month money market interest rate } \\
\text { Obtained from EEF section Exchange rates and Interest rates, line Mbney } \\
\text { market interest rates - Quarterly data, } \\
\text { series MAT_MD3 }\end{array}$ \\
\hline $\mathrm{i}_{\mathrm{t}}$ & $\begin{array}{l}\text { EU4national 3month money market interest rate } \\
\text { Obtained from EEF section Exchange rates and Interest rates, line Mbney } \\
\text { market interest rates - Quarterly data, series MAT_MO3 }\end{array}$ \\
\hline
\end{tabular}




\begin{tabular}{|l|l|}
\hline $\mathrm{m}_{\mathrm{t}}$ & $\begin{array}{l}\text { EU4national M1 monetary aggregate } \\
\text { Obtained from IFS line 34.B (Mbney, Seasonally Adjusted) and then } \\
\text { logged. }\end{array}$ \\
\hline $\mathrm{p}_{\mathrm{t}}^{*}$ & $\begin{array}{l}\text { Eurozone Harmonized indices of consumer prices } \\
\text { Obtained from EEF section Prices, line Harm onized indices of consumer } \\
\text { prices - Mbnthly data (index 2005=100). Converted from monthly to } \\
\text { quarterly data by averaging the three monthly figures and then logged. }\end{array}$ \\
\hline $\mathrm{p}_{\mathrm{t}}$ & $\begin{array}{l}\text { EU4national Harmonized indices of consumer prices } \\
\text { Obtained from EEF section Prices, line Harmonized indices of } \\
\text { consumer prices - Mbnthly data (index 2005=100). Converted } \\
\text { from monthly to quarterly data by averaging the three monthly } \\
\text { figures and then logged. }\end{array}$ \\
\hline
\end{tabular}

Appendix 2: Estimations of equations (14)-(16)

\begin{tabular}{|c|c|c|c|c|c|c|c|}
\hline \multicolumn{8}{|c|}{ Equation (14) } \\
\hline \multicolumn{4}{|c|}{ Czech Republic } & \multicolumn{4}{|c|}{ Hungary } \\
\hline \multicolumn{4}{|c|}{ instruments: $\Delta y_{t-1}^{\text {rend }} \Delta r_{t-1} \Delta i_{t-1} \Delta y_{t}^{\text {gap }} \quad \Delta p_{t-1}^{*}$} & \multicolumn{4}{|c|}{ instruments: $\Delta c_{t} \quad \Delta p_{t}^{*} \Delta i_{t-1} \Delta y_{t-1}^{t r e n d}$} \\
\hline param. & estim. & st.er. & prob. & param. & estim. & st.er. & prob. \\
\hline$\beta_{0}$ & 0.0019 & 0.0030 & 0.5350 & $\beta_{0}$ & -0.0047 & 0.0024 & 0.0508 \\
\hline$\beta_{1}$ & 0.0150 & 0.6767 & 0.9824 & $\beta_{1}$ & 0.4307 & 0.2758 & 0.1246 \\
\hline$\beta_{2}$ & -0.0401 & 0.0163 & 0.0175 & $\beta_{2}$ & -0.0490 & 0.0228 & 0.0364 \\
\hline \multicolumn{4}{|c|}{$\mathrm{R}^{2}=0.0784, \mathrm{SEE}=0.0094, \mathrm{DW}=1.9026$} & \multicolumn{4}{|c|}{$\mathrm{R}^{2}=0.1204, \mathrm{SEE}=0.0102, \mathrm{DW}=1.6233$} \\
\hline \multicolumn{4}{|c|}{$\begin{array}{l}\mathrm{J}-\mathrm{B}=35.786(0.0000), \mathrm{LM}=6.1672(0.1870) \\
\mathrm{WHITE}=24.917(0.0001)\end{array}$} & \multicolumn{4}{|c|}{$\begin{array}{l}\mathrm{J}-\mathrm{B}=0.8773(0.6448), \mathrm{LM}=21.709(0.0002) \\
\text { WHITE }=10.894(0.0278)\end{array}$} \\
\hline \multicolumn{4}{|c|}{ Poland } & \multicolumn{4}{|c|}{ Slovakia } \\
\hline \multicolumn{4}{|c|}{ instruments: $\Delta y_{t-1}^{t r e n d} \quad \Delta e_{t-1} \Delta i_{t-1} \Delta p_{t}^{*} \Delta c_{t-1}$} & \multicolumn{4}{|c|}{ instruments: $\Delta c_{t-1} \Delta p_{t-1}^{*} \Delta m_{t} \quad \Delta p_{t-1} \Delta i_{t-1}$} \\
\hline param. & estim. & st.er. & prob. & param. & estim. & st.er. & prob. \\
\hline$\beta_{0}$ & 0.0014 & 0.0022 & 0.5292 & $\beta_{0}$ & 0.0037 & 0.0038 & 0.3377 \\
\hline$\beta_{1}$ & 0.2229 & 0.1358 & 0.1068 & $\beta_{1}$ & -0.6755 & 0.6150 & 0.2772 \\
\hline$\beta_{2}$ & -0.0891 & 0.0319 & 0.0073 & $\beta_{2}$ & -0.0624 & 0.0418 & 0.1417 \\
\hline \multicolumn{4}{|c|}{$\mathrm{R}^{2}=-0.2486, \mathrm{SEE}=0.0101, \mathrm{DW}=2.3297$} & \multicolumn{4}{|c|}{$\mathrm{R}^{2}=-0.7455, \mathrm{SEE}=0.0165, \mathrm{DW}=1.6467$} \\
\hline \multicolumn{4}{|c|}{$\begin{array}{l}\mathrm{J}-\mathrm{B}=0.5631(0.7546), \mathrm{LM}=8.2077(0.0842) \\
\text { WHITE }=23.585(0.0001)\end{array}$} & \multicolumn{4}{|c|}{$\begin{array}{l}\mathrm{J}-\mathrm{B}=71.840(0.0000), \mathrm{LM}=4.2942(0.3676) \\
\text { WHITE }=1.1746(0.8823)\end{array}$} \\
\hline \multicolumn{8}{|c|}{ Equation (15) } \\
\hline \multicolumn{4}{|c|}{ Czech Republic } & \multicolumn{4}{|c|}{ Hungary } \\
\hline \multicolumn{4}{|c|}{ instruments: $\Delta p_{t}^{*} \Delta y_{t-1}^{t r e n d} \quad \Delta i_{t-1}^{*} \Delta e_{t-1}$} & \multicolumn{4}{|c|}{ instruments: $\Delta p_{t}^{*} \Delta y_{t-1}^{t r e n d} \quad \Delta c_{t} \quad \Delta p_{t-1}$} \\
\hline param. & estim. & st.er. & prob. & param. & estim. & st.er. & prob. \\
\hline$\alpha_{0}$ & 0.0027 & 0.0014 & 0.0680 & $\alpha_{0}$ & 0.0012 & 0.0010 & 0.2593 \\
\hline$\alpha_{1}$ & 0.9251 & 0.9693 & 0.3444 & $\alpha_{1}$ & 2.1007 & 0.9945 & 0.0396 \\
\hline$\alpha_{2}$ & 0.8499 & 0.3573 & 0.0211 & $\alpha_{2}$ & 0.9970 & 0.1780 & 0.0000 \\
\hline \multicolumn{4}{|c|}{$\mathrm{R}^{2}=-2.9594, \mathrm{SEE}=0.0058, \mathrm{DW}=1.7655$} & \multicolumn{4}{|c|}{$\mathrm{R}^{2}=0.1440, \mathrm{SEE}=0.0053, \mathrm{DW}=1.7237$} \\
\hline \multirow{2}{*}{\multicolumn{4}{|c|}{$\begin{array}{l}\mathrm{J}-\mathrm{B}=10.022(0.0066), \mathrm{LM}=8.7911(0.0665) \\
\mathrm{WHITE}=43.986(0.0000)\end{array}$}} & \multirow{2}{*}{\multicolumn{4}{|c|}{$\begin{array}{l}\mathrm{J}-\mathrm{B}=0.0137(0.9931), \mathrm{LM}=10.021(0.0401) \\
\mathrm{WHITE}=10.339(0.0351)\end{array}$}} \\
\hline & & & & & & & \\
\hline instrumen & $\Delta p_{t}^{*} \Delta e_{t-1}$ & $\Delta p_{t-1} \Delta$ & $\Delta p_{t-1}^{*}$ & instrumer & $\Delta i_{t}^{*} \Delta e_{t-1}$ & $\Delta y_{t}^{\text {trend }}$ & \\
\hline param. & estim. & st.er. & prob. & param. & estim. & st.er. & prob. \\
\hline$\alpha_{0}$ & 0.0002 & 0.0021 & 0.9153 & $\alpha_{0}$ & 0.0035 & 0.0023 & 0.1351 \\
\hline$\alpha_{1}$ & 2.8514 & 1.5569 & 0.0729 & $\alpha_{1}$ & 0.4775 & 1.8873 & 0.8013 \\
\hline$\alpha_{2}$ & 0.2191 & 0.0383 & 0.0000 & $\alpha_{2}$ & 0.4904 & 0.2243 & 0.0334 \\
\hline $\mathrm{R}^{2}=-0.00$ & $\mathrm{SEE}=0.0$ & $\mathrm{DW}=1$ & & $R^{2}=-0.68$ & $\mathrm{SEE}=0.0$ & $8, \mathrm{DW}=1$ & \\
\hline $\begin{array}{l}\mathrm{J}-\mathrm{B}=0.99 \\
\text { WHITE }=\end{array}$ & $\begin{array}{l}(0.6070) \\
510(0.24\end{array}$ & $\mathrm{A}=8.474$ & $.0756)$ & $\begin{array}{l}\mathrm{J}-\mathrm{B}=3.52 \\
\text { WHITE }=\end{array}$ & $\begin{array}{l}(0.1719), \\
479(0.11\end{array}$ & $\mathrm{M}=5.780$ & $.2162)$ \\
\hline
\end{tabular}

Source: Author's calculations 
A ppendix 2 (continued): Estimations of equations (14)-(16)

\begin{tabular}{|c|c|c|c|c|c|c|c|}
\hline \multicolumn{8}{|c|}{ Equation (16) } \\
\hline \multicolumn{4}{|c|}{ Czech Republic } & \multicolumn{4}{|c|}{ Hungary } \\
\hline \multicolumn{4}{|c|}{ instruments: $\Delta p_{t}^{*} \Delta y_{t}^{g a p} \Delta r_{t-1} \Delta i_{t}^{*} \Delta i_{t-1} \Delta y_{t-1}^{\text {trend }}$} & \multicolumn{4}{|c|}{ instruments: $\Delta y_{t}^{g a p} \quad \Delta i_{t-1}^{*} \Delta c_{t-1} \quad \Delta y_{t-1}^{g a p} \quad \Delta i_{t-1}$} \\
\hline param. & estim. & st.er. & prob. & param. & estim. & st.er. & prob. \\
\hline$\gamma_{0}$ & -0.0035 & 0.0033 & 0.2980 & $\gamma_{0}$ & 0.0017 & 0.0048 & 0.7150 \\
\hline$\lambda$ & -0.6998 & 0.1821 & 0.0003 & $\lambda$ & -0.6971 & 0.1128 & 0.0000 \\
\hline$\gamma_{1}$ & -0.5725 & 0.8973 & 0.5264 & $\gamma_{1}$ & -1.7175 & 0.7430 & 0.0250 \\
\hline$\gamma_{2}$ & 0.0003 & 0.0008 & 0.7334 & $\gamma_{2}$ & -0.0001 & 3.3E-05 & 0.0033 \\
\hline \multicolumn{4}{|c|}{$\mathrm{R}^{2}=0.3475, \mathrm{SEE}=0.0208, \mathrm{DW}=2.0566$} & \multicolumn{4}{|c|}{$\mathrm{R}^{2}=0.6565, \mathrm{SEE}=0.0119, \mathrm{DW}=2.5815$} \\
\hline \multicolumn{4}{|c|}{$\begin{array}{l}\mathrm{J}-\mathrm{B}=822.14(0.0000), \mathrm{LM}=0.4953(0.9739) \\
\mathrm{WHITE}=34.505(0.0000)\end{array}$} & \multicolumn{4}{|c|}{$\begin{array}{l}\mathrm{J}-\mathrm{B}=38.062(0.0000), \mathrm{LM}=13.386(0.0095) \\
\text { WHITE }=3.7906(0.7050)\end{array}$} \\
\hline \multicolumn{4}{|c|}{$\begin{aligned} \text { Poland } \\
\end{aligned}$} & \multicolumn{4}{|c|}{ Slovakia } \\
\hline \multicolumn{4}{|c|}{ instruments: $\Delta m_{t-1} \Delta p_{t}^{*} \Delta y_{t-1}^{n n d} \Delta p_{t-1}^{*} \Delta y_{t}^{g a p}$} & \multicolumn{4}{|c|}{ instruments: $\Delta y_{t-1}^{\text {trend }} \quad \Delta c_{t} \quad \Delta i_{t-1}^{*} \Delta y_{t-1}^{g a p} \Delta i_{t-1}$} \\
\hline param. & estim. & st.er. & prob. & param. & estim. & st.er. & prob. \\
\hline$\gamma_{0}$ & -0.0039 & 0.0030 & 0.1916 & $\gamma_{0}$ & 0.0083 & 0.0074 & 0.2693 \\
\hline$\lambda$ & -1.4245 & 0.3236 & 0.0001 & $\lambda$ & -0.9005 & 0.1252 & 0.0000 \\
\hline$\gamma_{1}$ & 1.4541 & 1.1559 & 0.2143 & $\gamma_{1}$ & -3.1911 & 2.3325 & 0.1779 \\
\hline$\gamma_{2}$ & -0.0003 & 0.0009 & 0.7247 & $\gamma_{2}$ & -0.0007 & 0.0021 & 0.7312 \\
\hline \multicolumn{4}{|c|}{$\mathrm{R}^{2}=0.7436, \mathrm{SEE}=0.0221, \mathrm{DW}=2.4557$} & \multicolumn{4}{|c|}{$\mathrm{R}^{2}=0.9512, \mathrm{SEE}=0.0224, \mathrm{DW}=2.4020$} \\
\hline \multicolumn{4}{|c|}{$\begin{array}{l}\mathrm{J}-\mathrm{B}=14.541(0.0007), \mathrm{LM}=8.9796(0.0616) \\
\text { WHITE }=3.9895(0.6780)\end{array}$} & \multicolumn{4}{|c|}{$\begin{array}{l}\mathrm{J}-\mathrm{B}=2.8966(0.2349), \mathrm{LM}=9.2211(0.0558) \\
\text { WHITE }=5.1728(0.8189)\end{array}$} \\
\hline
\end{tabular}

Source: Author's calculations

Appendix 3: Exchange market pressure in EU 4 countries (model-dependent approach)
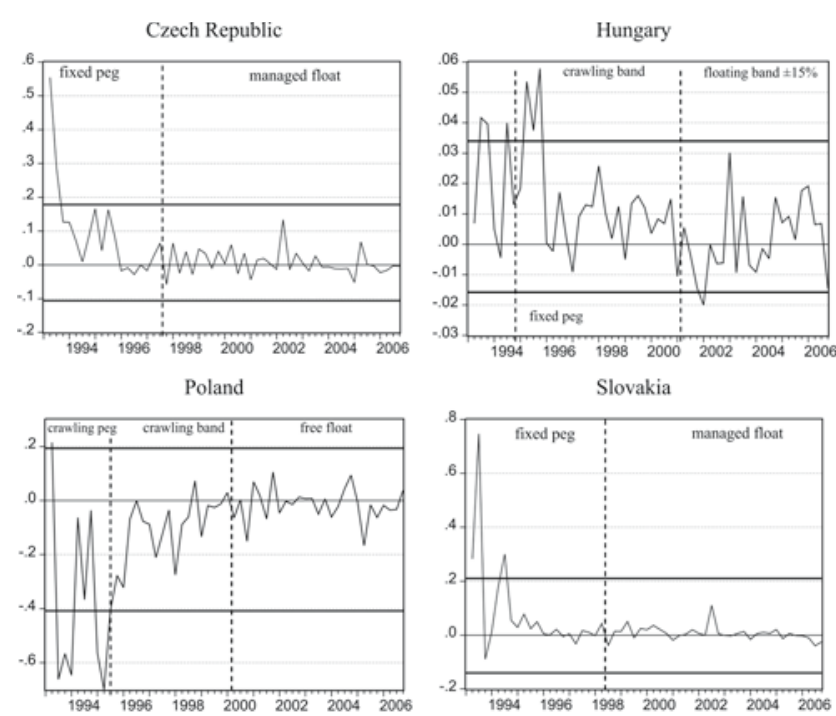

Source: Author's calculations

\section{A ppendix 4: Exchange market pressure in EU 4 countries (model-independent approach)}
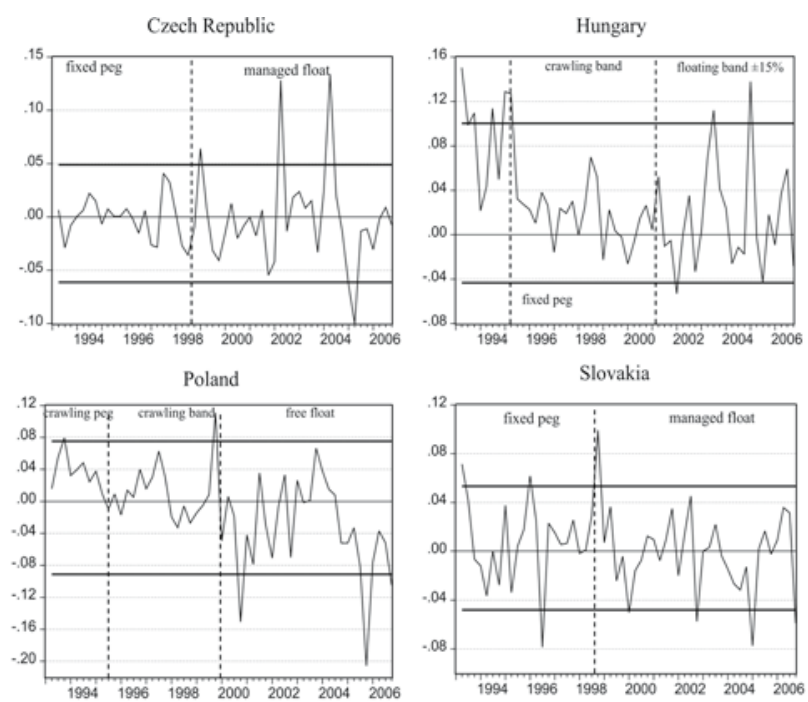

Source: Author's calculations 


\section{References}

Bielecki, S. 2005. Exchange market pressure and domestic credit evidence from Poland. The Poznan University of Economics Review 5(1): 20-36.

Eichengreen, B., A. K. Rose, C. Wyplosz. 1994. Speculative Attacks on Pegged Exchange Rates: an Empirical Exploration with Special Reference to the European Monetary System. Working Paper No. 4898. National Bureau of Economic Research.

1995. Exchange Market Mayhem: The Antecedents and Aftermath of Speculative Attacks. Economic Policy 10 (21): 249-312

Girton, L., D. Roper. 1977. A Mbnetary Mbdel of Exchange Market Pressure Applied to the Postwar Canadian Experience. American Economic Review 67 (4): 537-548.

Kaminski, G., S. Lizondo, C. Reinhart. 1998. Leading indicators of currency crises. IMF Staff Papers 45 (1): 1-48.

Kam inski, G., C. Reinhart. 1999. The twin crises: The causes of banking and balance-of-payments problems. American Economic Review 89(3): 473-500.

Pentecost, E. J., C. Van Hoydonk, A. Van Poeck. 2001. Measuring and Estimating Exchange Market Pressure in the EU. Journal of International Money and Finance 20 (3): 401418.

Roper, D., S. J. Turnovsky. 1980. Optimal Exchange Market Intervention in a Simple Stochastic Macro Mbdel. Canadian Journal of Economics 13(2): 296-309.

Sachs, J. D., A. Tornel, A. Velasco. 1996. Financial crises in emerging markets: The lessons from 1995. Brooking Papers on Economic Activity 1996(1): 147-215.

Spolander, M 1999. Measuring Exchange Market Pressure and Central Bank Intervention. Bank of Finland Studies E:17.

Stavárek, D. 2005. Exchange Market Pressure in New EU-member Countries. In Mbney, Banking and Financial Markets. Proceedings from the International Conference, 244-248. Bratislava: Ekonóm.

Tanner, E. 2002 Exchange Market Pressure, Currency Crises, and Mbnetary Policy: Additional Evidence from Emerging Markets. Working Paper WP/O2/14. International Monetary Fund.

Turnovsky, S. J. 1985. Optimal Exchange Market Intervention: Two Alternative Classes of Rules. In J. S. Bhandari (ed) Exchange Rate Management Under Uncertainty. Cambridge: MT Press.
Van Poeck, A., J. Vanneste, M Veiner. 2007. Exchange Rate Regimes and Exchange Market Pressure in the New EU Member States. Journal of Common Market Studies 45 (2): 459-485.

Weymark, D. N. 1995. Estimating Exchange Market Pressure and the Degree of Exchange Market Intervention for Canada. Journal of International Economics 39(3-4): 273295.

1997a. Measuring the Degree of Exchange Market Intervention in a Small Open Economy. Journal of International Money and Finance 16(1): 55-79.

1997b. Measuring Exchange Market Pressure and Intervention in Interdependent Economy: A Two-Country Model. Review of International Economics 5(1): 72-82

1998. A General Approach to Measuring Exchange Market Pressure. Oxford Economic Papers 50(1): 106-121. 